\title{
The K-Shaped Recovery: Examining the Diverging Fortunes of Workers in the Recovery from the COVID-19 Pandemic Using Business and Household Survey Microdata
}

\author{
Michael Dalton ${ }^{1}$ (D) - Jeffrey A. Groen ${ }^{1}$ (D) Mark A. Loewenstein ${ }^{1}$ • \\ David S. Piccone $\mathrm{Jr}^{1} \cdot$ Anne E. Polivka ${ }^{1}$
}

Received: 15 December 2020 / Accepted: 5 July 2021/Published online: 23 August 2021

(C) This is a U.S. government work and not under copyright protection in the U.S.; foreign copyright protection may apply 2021

\begin{abstract}
This paper examines employment patterns by wage group over the course of the coronavirus pandemic in the United States using microdata from two well-known data sources from the U.S. Bureau of Labor Statistics: the Current Employment Statistics and the Current Population Survey. We find establishments paying the lowest average wages and the lowest wage workers had the steepest decline in employment and experienced the most persistent losses. We disentangle the extent to which the effect observed for low wage workers is due to these workers being concentrated within a few low wage sectors of the economy versus the pandemic affecting low wage workers in a number of sectors across the economy. Our results indicate that the experience of low wage workers is not entirely due to these workers being concentrated in low wage sectors - for many sectors, the lowest wage quintiles in that sector also has had the worst employment outcomes. From April 2020 to May 2021, between 23\% and 46\% of the decline in employment among the lowest wage establishments was due to within-industry changes. Another important finding is that even for those who remain employed during the pandemic, the probability of becoming part-time for economic reasons increased, especially for lowwage workers.
\end{abstract}

Keywords Closures · Coronavirus · COVID-19 · Employment · Income $\cdot$ Inequality $\cdot$ Recession · Unemployment $\cdot$ Wages

Any analysis, opinions, and conclusions expressed herein are those of the authors and do not necessarily represent the views of the U.S. Bureau of Labor Statistics.

Michael Dalton

Dalton.Michael@bls.gov

Extended author information available on the last page of the article 


\section{Introduction}

The coronavirus (COVID-19) pandemic plunged the U.S. economy into recession in early 2020 and has fundamentally affected the labor market. As of mid-December 2020, COVID-19 was responsible for over 300,000 deaths in the United States. The unemployment rate rose from $3.5 \%$ in February 2020 to $14.7 \%$ in April before falling to $6.7 \%$ in November.

At the start of the pandemic, there were strong indications that the lowest-paid workers would be disproportionately affected. Analyzing the U.S. Bureau of Labor Statistics' (BLS) Quarterly Census of Employment and Wages and Occupational Employment Statistics data, Dey and Loewenstein (2020) showed that low-paid occupations were heavily represented and high-paid occupations lightly represented in the industry sectors most susceptible to employment losses during the pandemic. Using data from BLS's Current Population Survey (CPS), Dey et al. (2020) found that in 2019, the median hourly wage of workers in highly exposed sectors was $\$ 15.00$, compared to $\$ 21.50$ for workers in other sectors. Furthermore, a larger share of workers in highly exposed sectors worked part-time hours in 2019.

Analysis of private data from various sources appears to bear out that low wage workers have borne the brunt of the pandemic induced recession. Using data from ADP, a large payroll processor, to analyze labor market trends through June 2020, Cajner et al. (2020) found employment losses to be largest among workers in the lowest quintile, where quintiles are defined on the basis of workers' hourly wage in February data. In their data, by mid-April workers in the lowest quintile had experienced a decline in employment of about $35 \%$ relative to mid-February levels; as of late June, employment had recovered but was still $20 \%$ lower than mid-February. Bartik et al.'s (2020) findings using Homebase work records provide further evidence that low wage workers have fared poorly during the early part of the recession. Their sample, which is skewed toward lower wage workers in the hospitality/ restaurant sector, shows that as of mid-April the number of hours worked by workers with a wage below $\$ 15$ an hour was about $75 \%$ below the level in late January while the hours of workers with wage above $\$ 15$ was about $60 \%$ below the January level. By June, the hours of all workers in their sample had recovered to about $50 \%$ to $60 \%$ of the January level.

Chetty et al. (2020) combined payroll processing information from Paychex and Intuit and financial management data from Earnin to analyze employment declines through August 2020 for workers grouped into three wage classes. The Opportunity Insights Economic Tracker indicated that employment bottomed out in the third week of April, at which time the employment level for workers with annual earnings below $\$ 27,000$ was $37.4 \%$ below the level in January. For workers earning between $\$ 27,000$ and $\$ 60,000$, this figure was $23.3 \%$, and it was $13.7 \%$ for workers earning more than $\$ 60,000$. By the third week in August, the employment level of workers in the lowest earnings group was still $17.5 \%$ below the January level. In contrast, the employment of workers in the middle earnings group was $5.4 \%$ below the January level and the employment of high wage workers had nearly recovered completely, as it was only $1 \%$ below its level in January.

This paper provides a further look at employment patterns by wage group over the course of the pandemic using microdata from two BLS data sources: the Current Employment Statistics (CES) and the Current Population Survey (CPS). In contrast to the datasets described above, the CES survey offers a large, representative sample of employers and the CPS offers a large, representative sample of workers. We also present additional evidence from the Business Response Survey to the Coronavirus Pandemic, a special BLS survey that collected establishments' responses to a series of questions related to businesses' experiences during the pandemic. 
An important aspect of our work is an exploration of workers within industry sectors. This allows us to disentangle the extent to which the effect observed for low wage workers is due to these workers being concentrated within low wage sectors of the economy versus the pandemic affecting low wage workers in a number of sectors across the economy. A withinindustry exploration also allows us to examine whether there were some industries in which the effects of the pandemic were more uniformly distributed across workers with different levels of earnings than other industrial sectors. The within- and across-industry analysis has important implications for the effect of the pandemic on evolving earnings inequality and attempts to address the potential widening of earnings disparities in the U.S. economy. If the effects on low wage workers are concentrated in specific industries, this may call for more targeted support of specific industries. Instead, if low wage workers suffer disproportionately across all industries, the pursuit of more economy-wide actions may be warranted.

We present two key findings. First, establishments paying the lowest average wages and the lowest wage workers had the steepest decline in employment and experienced the most persistent losses as of the last months of our analysis (May 2021 for the CES and November 2020 for the CPS). The second key finding is that these effects are not entirely explained by industry effects - for many sectors, the lowest wage quintile in that sector also had the worst employment outcomes. Previous research has shown the long-run consequences of an unemployment spell to workers during a recession, such as significant lifetime earnings displacement (Davis and Von Wachter 2011) and higher risk of mortality (Sullivan and Von Wachter 2009). Furthermore, many of these negative outcomes have been worse for low-wage workers. Chetty et al. (2016) observed considerable inequality in mortality rates across the income spectrum with higher income being associated with greater longevity. Heathcote et al. (2020) found in all U.S. recessions in the last half century, low wage workers - particularly menexperienced the largest decline in earnings and hours and that these losses were not fully recovered in subsequent expansions. Similarly, Yagan (2019) documented persistent employment rate declines and a slow jobless recovery for low wage workers in the wake of the Great Recession. These results clearly suggest the pandemic recession may lead to significant and persistent increases in inequality.

Another important finding in this paper using the household survey is that even for those who remain employed during the pandemic, there is a higher probability of becoming parttime for economic reasons, in particular for low-wage workers. This is additional evidence showing the multiple paths through which low-wage workers struggled during the pandemic and indicates another dimension on which low-wage workers have to recover in order to regain their pre-pandemic labor force status.

\section{Using the CES and CPS to Track Employment}

To examine employment from an establishment perspective, we use microdata from the Current Employment Statistics (CES) survey. The CES is one of the longest running and most relied upon sources of current data on the U.S. labor market. The CES is a monthly survey that collects data from 145,000 businesses and government agencies representing 697,000 worksites. The survey asks about employment, hours, and earnings in the pay period that includes the 12th of the month. Preliminary estimates at the national level by industry are usually published on the first Friday of the following month, with revisions published in the 2 succeeding months. We track employment changes using monthly data starting in February 
2020 and going through May 2021. We use information from the prior year's Quarterly Census of Employment and Wages (QCEW) to obtain wage information for the establishments interviewed in the CES. ${ }^{1}$ Furthermore, we use the average monthly employment in 2019 in the QCEW as the baseline employment for each employer in the CES.

For an examination from the workers' perspective, we use microdata from the Current Population Survey (CPS). Conducted by the U.S. Census Bureau for BLS, the CPS is a monthly survey of 60,000 households that collects information about demographics, labor force status, earnings, hours worked, and occupation and industry of people's jobs. Similar to the CES, the reference period includes the 12th of the month. We track employment changes using monthly data starting in March 2020 and going through November 2020, the latest date individuals can be reliably matched before and after the pandemic. For our analysis we rely on the longitudinal aspect of the CPS: we observe wage information for employed individuals interviewed in 2019 along with other important employment information for an individual prior to the pandemic. We then observe their labor force status and hours worked in 2020 during the pandemic.

\section{CES Analysis}

Each establishment is grouped into a wage class, defined as an establishment's average wage per worker in 2019: the establishment's total annual wages in 2019 in the QCEW divided by the establishment's average monthly employment across all 12 months of 2019 in the QCEW. ${ }^{2}$ Table 1 shows the proportion of establishments and employment in each category.

The key results constructed for this section are based on the methodology described in Dalton et al. (2020). In that paper, estimates for changes in employment by size class are constructed for each month relative to an establishment's reported employment in February 2020, exploiting the panel-sample structure of the CES. A similar strategy is used here, but with a few key changes. First, the average monthly employment in 2019 is used as the baseline instead of reported employment in February in the CES. This change does two things: it smooths over any seasonality that having February as a baseline may cause, and it allows us to expand the analytical sample to include every sampled respondent each month instead of having to rely on only sampled respondents that had given a response in the prior February. Second, instead of dividing establishments by size class, establishments are grouped by wage class for the analysis in this paper.

The total change in employment for each wage class is the sum of two separate components:

1) The employment change in establishments continuing with positive employment, which is assumed to be the same for both respondents and nonrespondents.

2) Employment decline due to closures. Closures for respondents are based on reported zero employment in the data. Closures for nonrespondents are imputed based on historical data showing an increased likelihood for nonrespondents to be closed. Closures will only have

\footnotetext{
${ }^{1}$ The QCEW provides the sampling frame for the CES and other BLS establishment surveys. The QCEW program also publishes estimates of employment and wages. QCEW data are collected from the full universe of employers covered by Unemployment Insurance programs in the United States.

${ }^{2}$ All references to wages in the CES are nominal dollar amounts not adjusted for inflation.
} 
Table 1 Establishment and Employment Distribution, by Average Wages in the Establishment

\begin{tabular}{lll} 
Average wage per worker & Proportion of Establishments, as of 2019 & Proportion of Employment, as of 2019 \\
\hline$<\$ 20 \mathrm{k}$ & 0.28 & 0.14 \\
$\$ 20 \mathrm{k}-\$ 40 \mathrm{k}$ & 0.29 & 0.27 \\
$\$ 40 \mathrm{k}-\$ 60 \mathrm{k}$ & 0.18 & 0.24 \\
$\$ 60 \mathrm{k}-\$ 80 \mathrm{k}$ & 0.09 & 0.15 \\
$\$ 80 \mathrm{k}+$ & 0.17 & 0.20 \\
\hline
\end{tabular}

Note: ' $\mathrm{k}$ ' means thousands

a negative impact on employment, whereas the component for continuing establishments may be positive or negative. In our analysis, a sampled establishment will remain in our analysis regardless of closure status, and if it opens up again, it will move back to the continuing establishment estimates described above.

The employment for establishment $i$ in month $M$, wage class $j$, and sector $k$ is designated by $E_{i M j k}$. Letting $R_{M}$ denote the set of sampled establishments in month $M$, which is the union of $R_{M}^{\text {Continuing }}$ (the set of responding establishments that continue to be open in month $M$ ), $R_{M}^{\text {Closed }}$ (the set of responding establishments that report zero employment in month $M$ ), and $R_{M}^{\prime}$ (the set of sampled employers that were nonrespondents in month $M$ ). The percentage employment change for continuing establishments (those with positive employment in month $M$ ) who respond in month $M$, wage class $j$, and sector $k$ is depicted as

$$
\% \Delta E_{R M j k}^{\text {Continuing }}=\frac{\sum_{i \in R_{M}^{\text {Continuing }}} E_{i M j k}-E_{i y^{2019} j k}}{\sum_{i \in R_{M}^{\text {Continuing }}} E_{i y^{2019} j k}}
$$

$E_{i y^{2019} j k}$ represents the average monthly employment for the full calendar year of 2019 for the establishment. The level of employment change, $\triangle E M P_{M j k}^{\text {Continuing }}$, for all continuing establishments (including nonrespondents) in month $M$, wage class $j$, and sector $k$ is then given by

$$
\Delta E_{M j k}^{\text {Continuing }}=\% \Delta E_{R M j k}^{\text {Continuing }}\left[\sum_{i \in R_{M}^{\text {Continung }}}\left\lceil E_{i y^{2019} j k}\right\rceil+\left(1-\widehat{c_{M j k}}\right) * \sum_{i \in R_{M}^{\prime}}\left\lceil E_{i y^{2019} j k}\right\rceil\right]
$$

The first summation is for continuing respondents with a valid response in month $M$, and the second summation over $R_{M}^{\prime}$, all nonresponding establishments, is the imputed employment for nonrespondents that are estimated to be continuing establishments in month $M$. For the imputed employment, continuing establishments are assumed to have the same percentage change in employment as responding continuing establishments. $\widehat{c_{M W j k}}$ is the estimated probability of closure for nonresponding establishments. ${ }^{3}$

The estimate of the percentage change in employment for establishments that continue to be open can then be expressed as

\footnotetext{
$\overline{3}$ Details of how this is calculated are explained in Dalton, Handwerker, and Loewenstein (2020). It is the product of the percentage of responding employers that report zero employment in month $M$ and an adjustment.
} 


$$
\% \Delta E_{M j}^{\text {Continuing }}=\frac{\sum_{k} \Delta E_{M j k}^{\text {Continuing }}}{\sum_{k} \sum_{i \in R_{M}} E_{i y^{2019} j k}}
$$

where the denominator is the employment level at all responding establishments in the prior year $\left(y^{2019}\right)$ who were still in the sample as of month $M$.

The estimated change in the employment level for closed establishments is

$$
\Delta E_{M j k}^{\text {Closed }}=\left[\sum_{i \in R_{M}^{\text {Closed }}}\left\lceil-E_{i y^{2019} j k}\right\rceil \widehat{c_{M j k}} * \sum_{i \in R_{M}^{\prime}}\left\lceil E_{i y^{2019} j k}\right\rceil\right]
$$

and the percentage change is

$$
\% \Delta E_{M j}^{\text {Closed }}=\frac{\sum_{k} \Delta E_{M j k}^{\text {Closed }}}{\sum_{k} \sum_{i \in R_{M}} E_{i y^{2019} j k}}
$$

Finally, the percentage employment change for wage class $j$ in month $M$ (relative to employment in 2019) is

$$
\% \Delta E_{M j}=\% \Delta E_{M j}^{\text {Continuing }}+\% \Delta E_{M j}^{\text {Closed }}
$$

Figure 1 depicts the two components of the overall employment change each month for that wage class, $\% \Delta E_{M j}^{\text {Continuing }}$ and $\% \Delta E_{M j}^{\text {Closed }}$.

The results in Fig. 1 show that for the top two wage classes, employment loss due to closures stayed between 1\% and 2.2\% from April 2020 through May 2021. Starting in April 2020 , for the remaining wage classes, the loss of employment due to closures gets progressively larger as wages decrease, with the middle wage class hovering around $2 \%$ after May 2020, the second lowest wage class remaining at about 3\% after June 2020, and the lowest wage class staying at 7\% after May 2020. Since March 2021, a year into the pandemic recession, the top three wage classes have had an increase in employment for continuing establishments, whereas the bottom two wage classes remain negative for continuing establishments relative to the 2019 baseline.

Summing the two components in Fig. 1, the lines in Fig. 2a depict the total percentage change in the employment of each wage class every month. The lowest-wage establishments consistently have the largest employment decline each month. Although the lowest-paying establishments had some bounce back from the 34\% fall in their employment in April 2020, their employment a year later in April 2021 was still 10.5\% below their level in 2019, and May 2021 estimates were $7 \%$ lower. ${ }^{4}$ The percentage change in employment in May 2021 for the three highest wage classes is actually positive, meaning they have fully recovered and exceeded their employment levels relative to their 2019 baseline.

As a comparison to the pandemic-exposed employment pattern in 2020, Fig. 2b shows analogous results for 2019 in order to illustrate that the 2020 pattern is not explained by

\footnotetext{
${ }^{4}$ The April and May 2021 estimates are based on the preliminary data used in the June 2021 Employment Situation news release
} 
\% Employment Change since 2019

by Wage Class and Component of Change
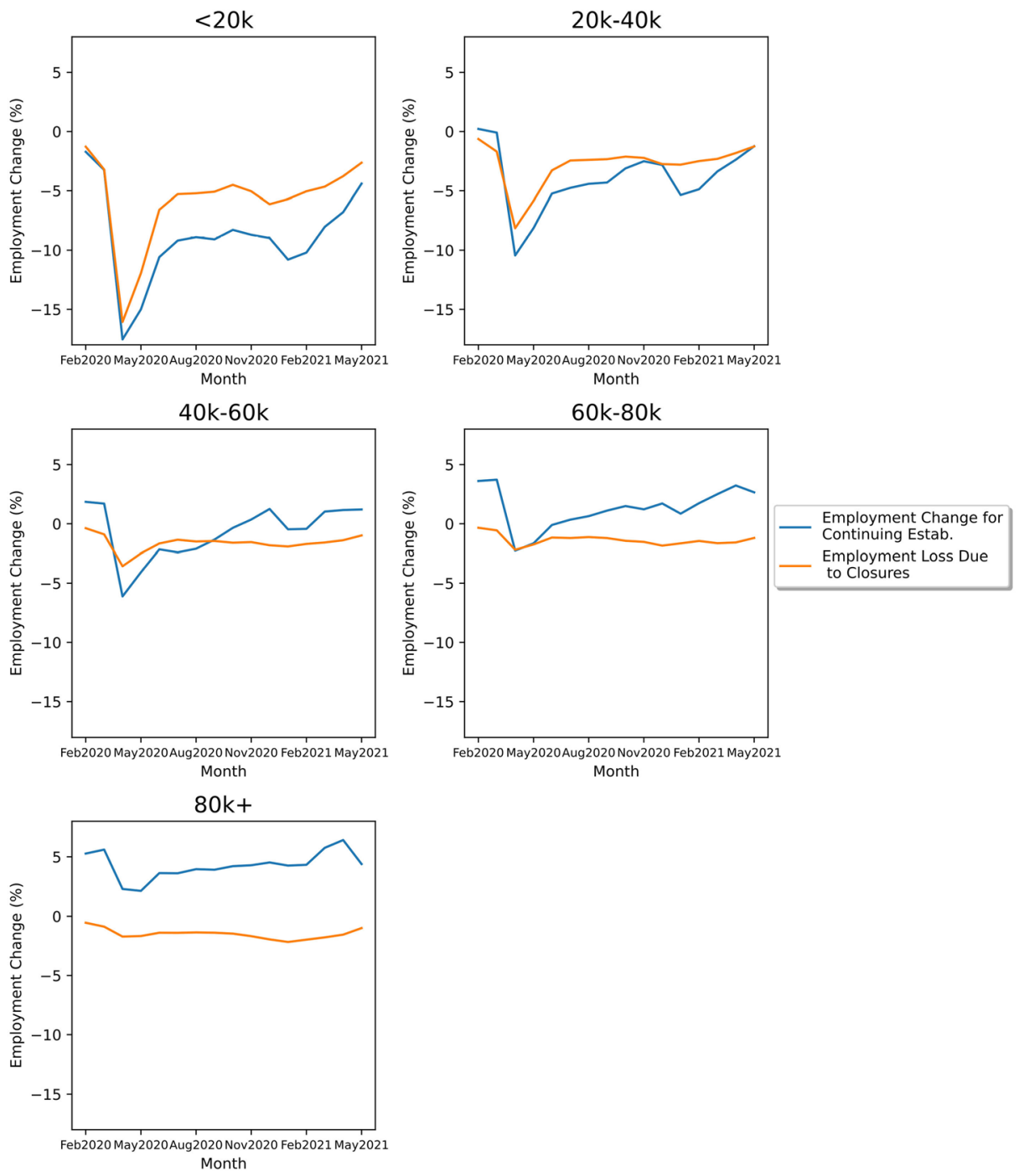

Fig. 1 Percentage Employment Change since 2019, by Wage Class, CES Data

seasonality or normal churn. Scales are kept the same for comparison. The most apparent takeaway from Fig. $2 \mathrm{~b}$ is the magnitude of employment loss experienced in 2020. The patterns observed in 2019 also do not seem to offer much of an explanation of what was observed in 2020 and 2021.

Figure 2c again shows the analogous graph, but for the Great Recession time period, using the 4 quarters prior to the start of the recession (4th Quarter 2006 through 3rd Quarter 2007) as the baseline for employment for each establishment. Again, this graph puts the sudden, dramatic drop in employment observed in 2020 in perspective, illustrating its uniqueness. Compared to the 2020 pandemic recession, the decline in employment was much more gradual 

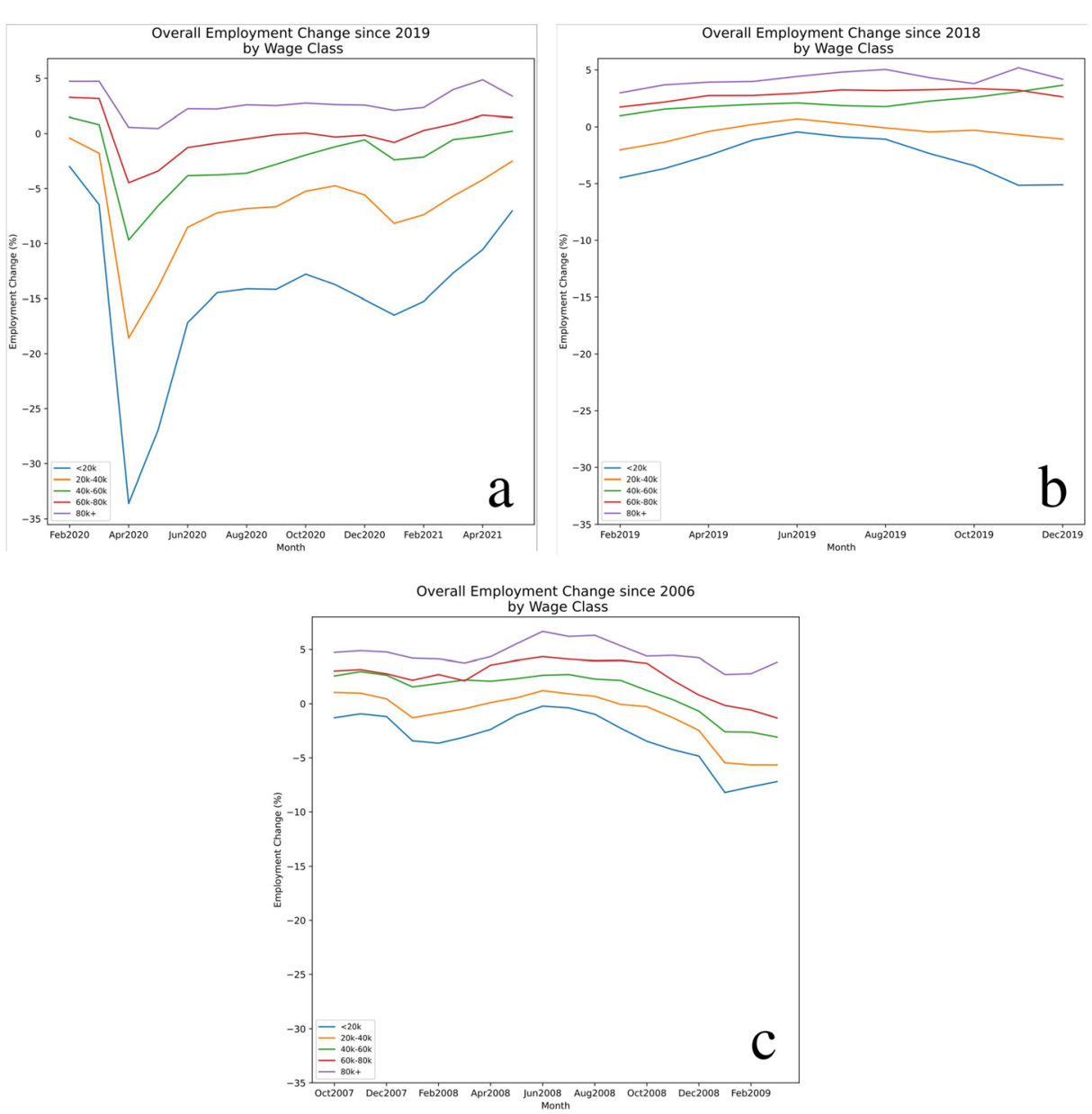

Fig. 2 a. Overall Percentage Employment Change for 2020-2021, relative to 2019, CES Data, b. Overall Percentage Employment Change for 2019, relative to 2018, CES Data, c. Overall Percentage Employment Change for Great Recession, Relative to Prior Four Quarters Employment, CES Data

during the Great Recession. Also unlike the pandemic recession when low wage workers suffered disproportionately larger loss of employment, during the Great Recession the loss of employment was more uniformly distributed across wage classes. Each wage class in the Great Recession experienced an overall trend downward over the 18 months depicted in the graph.

A natural question is whether the relatively large employment declines at establishments paying lower wages simply reflect a drop in employment in low-wage industrial sectors such as other services and leisure and hospitality. We therefore now repeat our analysis for each of the sectors. Figure 3 shows employment changes within sector for establishments in each of the wage classes, using the same wage cutoffs across sectors. Interestingly, the employment patterns within the various sectors are mostly similar to the overall pattern portrayed in Fig. 2a. Even within sectors, the lowest wage establishments disproportionately suffered the largest losses in employment. Specifically, in 11 of the 15 sectors, the lowest wage establishments within the sector have the biggest percentage declines in employment as of 
Employment Change since 2019

by Wage Class and Industry
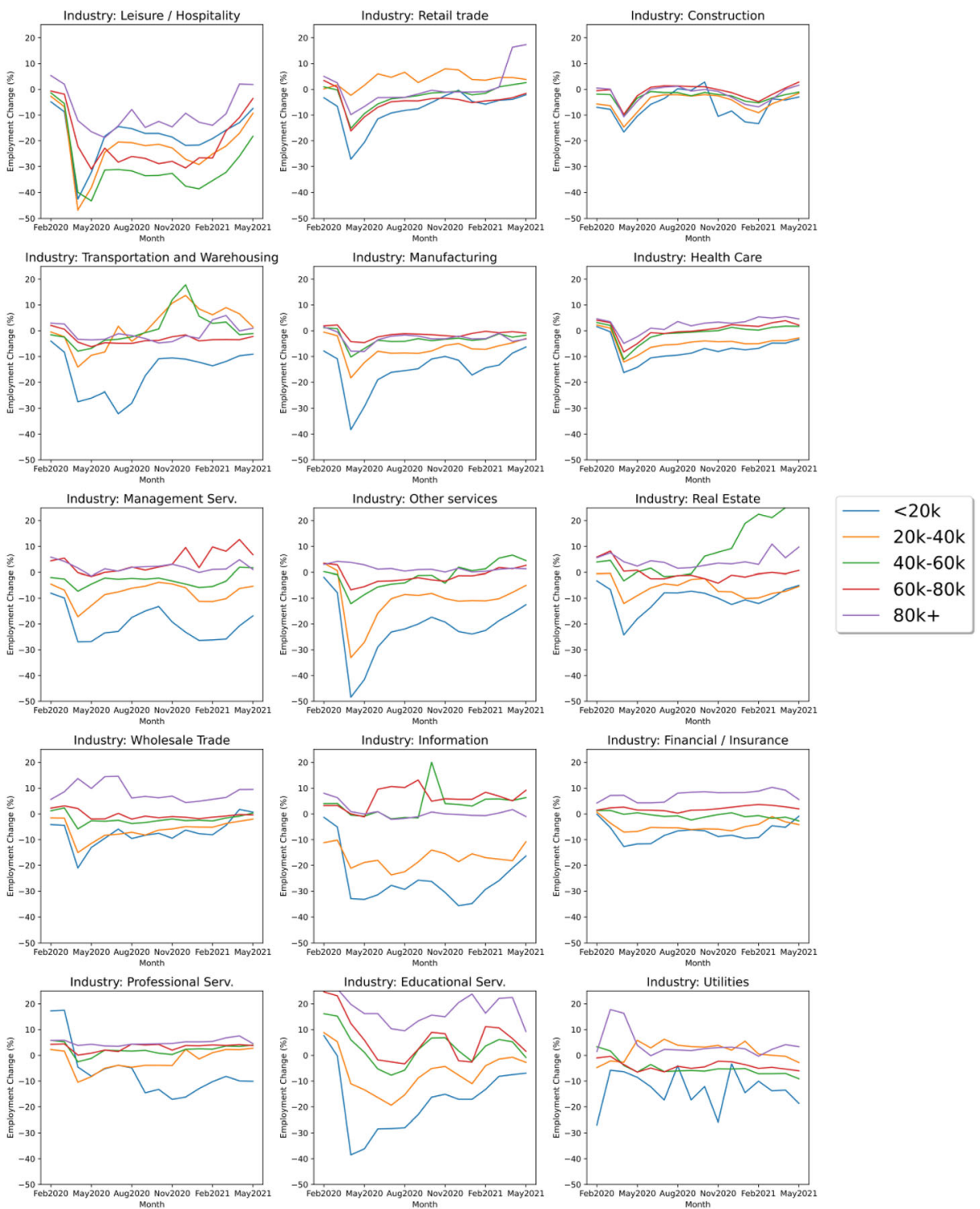

Fig. 3 Employment Change since 2019 by Wage Class and Industry, CES Data

May 2021. Even within the typically low-wage sectors such as other services, establishments that paid the lowest wages had disproportionately larger declines in employment. Similarly within the higher wage sectors such as information and professional services, it was the establishments that paid the lowest wages that had the biggest declines in employment. The fact that low-wage establishments suffered the largest declines in employment across most of the sectors establishes that the 
aggregate results presented in Fig. 2 are not simply due to low-wage industrial sectors of the economy being disproportionally affected by the pandemic.

\section{Decomposition of Employment Change in the CES}

In order to quantify how much of the employment loss is due to employment declines at the industry level and how much is due to changing proportions of employment in each wage class within major industry sector, we construct a decomposition of employment change into these two components.

Let $E_{k j t}$ denote employment in wage class $j$ and sector $k$ in month $t, W_{j t}$ denote the total employment in wage class $j$ in month $t$, and $N_{k t}$ denote the total employment in sector $k$ in month $t$. Also, let $E_{k j 0}$ denote employment in wage class $j$ and sector $k$ in 2019, $W_{j 0}$ denote the total employment in wage class $j$ in 2019, and $N_{k 0}$ denote the total employment in sector $k$ in 2019. Then

$$
\begin{aligned}
& \Delta W_{j t}=W_{j t}-W_{j 0} \\
& =\sum_{k} E_{k j t}-\sum_{k} E_{k j 0}\left[\frac{E_{k j t}}{N_{k t}} N_{k t}-\frac{E_{k j 0}}{N_{k 0}} N_{k t}+\frac{E_{k j 0}}{N_{k 0}} N_{k t}\right]-\sum_{k}\left[\frac{E_{k j 0}}{N_{k 0}} N_{k 0}\right] \\
& =\sum_{k}\left[\left(\frac{E_{k j t}}{N_{k t}}-\frac{E_{k j 0}}{N_{k 0}}\right) N_{k t}\right]+\sum_{k}\left[\frac{E_{k j 0}}{N_{k 0}}\left(N_{k t}-N_{k 0}\right)\right] \\
& =\sum_{k}\left[\left(s_{k j t}-s_{k j 0}\right) N_{k t}\right]+\sum_{k}\left[s_{k j 0}\left(N_{k t}-N_{k 0}\right)\right]
\end{aligned}
$$

where $s_{k j t}=\frac{E_{k j t}}{N_{k t}}$ is the share of employment in sector $k$ composed of wage class $j$ and $s_{k j 0}=\frac{E_{k j 0}}{N_{k 0}}$ is the share of employment in sector $k$ composed of wage class $j$ in 2019. Letting $t=0$ represent 2019 and dividing both sides of Eq. (7) by $W_{j o}$ allows us to express the percentage change in employment for wage class $j$ since 2019 as the sum of two components:

$$
\% \Delta W_{j t}=\frac{\overbrace{\sum_{k}\left[\left(s_{k j t}-s_{k j 0}\right) N_{k t}\right]}^{\text {Shifting Share of Wage Class }}}{W_{j 0}}+\frac{\overbrace{\sum_{k}\left[s_{k j 0}\left(N_{k t}-N_{k 0}\right)\right]}^{\text {Change in Sectoral Employment }}}{W_{j 0}}
$$

The first term on the right side of Eq. (8) represents the employment change due to a shift since 2019 in wage class $j$ 's share of employment in each industry sector. If sectors across the economy shed low wages workers so that the share of low-wage workers within each sector changed, this would be reflected in the first term. If, instead, the employment change we observed above was entirely explained by specific low-wage sectors decreasing employment and the share of low-wage workers in each sector remaining the same, this first term would be zero.

The second term represents the change in employment due strictly to changes in employment across sectors. This term reflects how much of the decline in low-wage employment is due to the decline in employment for low-wage sectors initially employing a larger share of low-wage workers. The larger the decline in employment for low-wage sectors, the larger the second term will be.

The results from this decomposition are presented in Table 2, which shows results for April 2020, July 2020, October 2020, and May 2021. The third column is the share of employment 
Table 2 CES Decomposition by Major Industry Sector

\begin{tabular}{|c|c|c|c|}
\hline Wage quintile & Employment change (\%) & $\begin{array}{l}\text { Due to between-sector } \\
\text { reallocation }(\%)\end{array}$ & $\begin{array}{l}\text { Due to within-sector } \\
\text { reallocation }(\%)\end{array}$ \\
\hline \multicolumn{4}{|l|}{ A. April 2020} \\
\hline$<\$ 20 \mathrm{k}$ & -33.6 & -25.4 & -8.2 \\
\hline$\$ 20 \mathrm{k}-\$ 40 \mathrm{k}$ & -18.6 & -16.6 & -2.0 \\
\hline$\$ 40 \mathrm{k}-\$ 60 \mathrm{k}$ & -9.7 & -10.4 & 0.7 \\
\hline$\$ 60 \mathrm{k}-\$ 80 \mathrm{k}$ & -4.5 & -8.5 & 4.0 \\
\hline$\$ 80 \mathrm{k}+$ & 0.6 & -5.8 & 6.4 \\
\hline \multicolumn{4}{|l|}{ B. July 2020} \\
\hline$<\$ 20 \mathrm{k}$ & -14.5 & -11.9 & -2.5 \\
\hline$\$ 20 \mathrm{k}-\$ 40 \mathrm{k}$ & -7.2 & -6.4 & -0.8 \\
\hline$\$ 40 \mathrm{k}-\$ 60 \mathrm{k}$ & -3.8 & -3.4 & -0.3 \\
\hline$\$ 60 \mathrm{k}-\$ 80 \mathrm{k}$ & -0.9 & -2.3 & 1.4 \\
\hline$\$ 80 \mathrm{k}+$ & 2.2 & -0.8 & 3.0 \\
\hline \multicolumn{4}{|l|}{ C. October 2020} \\
\hline$<\$ 20 \mathrm{k}$ & -12.8 & -10.0 & -2.8 \\
\hline$\$ 20 \mathrm{k}-\$ 40 \mathrm{k}$ & -5.2 & -4.5 & -0.7 \\
\hline$\$ 40 \mathrm{k}-\$ 60 \mathrm{k}$ & -1.9 & -2.0 & 0.1 \\
\hline$\$ 60 \mathrm{k}-\$ 80 \mathrm{k}$ & 0.1 & -1.1 & 1.2 \\
\hline$\$ 80 \mathrm{k}+$ & 2.7 & 0.2 & 2.5 \\
\hline \multicolumn{4}{|l|}{ D. May 2021} \\
\hline$<\$ 20 \mathrm{k}$ & -7.0 & -3.8 & -3.3 \\
\hline$\$ 20 \mathrm{k}-\$ 40 \mathrm{k}$ & -2.5 & -1.5 & -1.0 \\
\hline$\$ 40 \mathrm{k}-\$ 60 \mathrm{k}$ & 0.2 & -0.4 & 0.6 \\
\hline$\$ 60 \mathrm{k}-\$ 80 \mathrm{k}$ & 1.5 & 0.1 & 1.4 \\
\hline$\$ 80 \mathrm{k}+$ & 3.4 & 0.7 & 2.7 \\
\hline
\end{tabular}

Note: ' $\mathrm{k}$ ' means thousands

lost due to shifting employment across sectors, and the fourth column is the share of employment lost due to shifting employment within sectors, but across wage classes. These two columns sum to the total employment change in the second column. (The decomposition results for every month are reported in Appendix Table 1.)

The estimates show that only the lowest two wage classes had a consistently negative employment decline due to shifts in wage-class shares within sectors. Furthermore, the lowest wage class is the only class for which the employment loss due to within-sector reallocation was greater than 2\% at any point between April 2020 and May 2021. This indicates that employment is moving away from the lowest-wage class within sectors. As of May 2021, 54\% of overall employment loss for the lowest wage class was due to between-sector change, while within-sector share change accounted for the remaining $46 \%$.

Appendix Table 2 shows the decomposition using 4-digit NAICS industry code instead of the broader sector as the industry grouping. This decomposition should show less employment loss due to within-industry share shifting since presumably 4-digit industries are more homogenous than establishments in the same sector, the latter being a broader classification. Nevertheless, the same pattern observed in Table 2 also holds for Appendix Table 2. Even when using the more detailed industry classification, employment loss due to shifting away from the lowest-wage class within industry makes up more than a third of the total employment loss as of May 2021. Although across-sector employment change is the dominant factor, 
Table 3 CES Decomposition by Sector, Great Recession, March 2009

\begin{tabular}{llll}
\hline $\begin{array}{l}\text { Wage } \\
\text { quintile }\end{array}$ & $\begin{array}{l}\text { Employment change } \\
(\%)\end{array}$ & $\begin{array}{l}\text { Due to between-sector reallocation } \\
(\%)\end{array}$ & $\begin{array}{l}\text { Due to within-sector reallocation } \\
(\%)\end{array}$ \\
\hline$<20 \mathrm{k}$ & -7.2 & -4.6 & -2.6 \\
$\$ 20 \mathrm{k}-\$ 40 \mathrm{k}$ & -5.7 & -4.1 & -1.6 \\
$\$ 40 \mathrm{k}-\$ 60 \mathrm{k}$ & -3.1 & -4.4 & 1.3 \\
$\$ 60 \mathrm{k}-\$ 80 \mathrm{k}$ & -1.3 & -4.5 & 3.2 \\
$\$ 80 \mathrm{k}+$ & 3.8 & -3.8 & 7.6 \\
\hline
\end{tabular}

Note: ' $\mathrm{k}$ ' means thousands

within-sector share shifting is sizeable and shows employment loss is happening in low-wage establishments across the economy.

Table 3 shows the decomposition for the Great Recession as of March 2009, allowing for close to the same amount of time to have passed for the Great Recession as had passed for the pandemic recession as of May 2021. A pattern similar to that in Table 2 can be seen for the Great Recession where the lowest wage classes see a sizeable portion of the employment decline explained by within-sector share shifting, although it is only $36 \%$ of the change in March 2009, compared to $46 \%$ as of May 2021.

\section{CPS Analysis}

Each household in the CPS is scheduled to be interviewed for four consecutive months and then, eight months later, is interviewed for another four consecutive months. Since questions about earnings are asked only in the fourth and eighth interviews, we use information collected in workers' fourth interview in 2019 to determine, at the time of the interview, an employed worker's earnings, hours worked, occupation, and industry. We then examine the labor force status and hours of work for these workers for every month between February 2020 and November 2020. This yields a sample of approximately 18,500 individuals from February through September, 14,600 in October, and 9700 in November. The sample reduction in the final two months is caused by the rotational nature of the CPS interview schedule. In October and November there are fewer individuals that provided earnings data in 2019; some of those interviewed in these months conducted their fourth interview in the beginning months of 2020 , making them ineligible for our sample. To account for the reduction of observations caused by the rotation pattern of interviewing and attrition, we adjusted the weights used in our analysis to preserve the average age, race, and gender distribution of workers in 2019. Each worker is grouped into a wage class on the basis of their weekly earnings in $2019 .^{5}$ The CPS weekly earnings quintile definitions are presented in Table 4.

The sample each month consists of workers who were interviewed that month and also employed the last time they were interviewed in $2019 .^{6}$ Figure 4 displays the proportion of

\footnotetext{
${ }^{5}$ Earnings quintiles are defined based on real weekly earnings from 2019. All weekly earnings for each month in 2019 were adjusted using the CPI-U to a February 2020 reference period.

${ }^{6}$ Throughout the remainder of the discussion we refer to these workers as "still employed" or "remained employed". Despite the use of these terms, we do not mean to imply that these workers were continuously employed, but rather these workers were employed the last time we observed them in 2019 and in the month under discussion in 2020. Workers could have experienced a period of non-employment in between.
} 
Table 4 CPS Weekly Earnings Quintile Definitions

\begin{tabular}{cl}
\hline Quintile & Weekly Earnings \\
\hline 1 & Less than $\$ 444$ \\
2 & $\$ 444-\$ 680$ \\
3 & $\$ 680-\$ 978$ \\
4 & $\$ 978-\$ 1518$ \\
5 & More than $\$ 1518$ \\
\hline
\end{tabular}

workers in each earnings quintile who were still employed each month from February 2020 to November 2020, thereby illustrating the evolution of employment during the pandemic by earnings quintile. The proportion of workers who were still employed in February 2020 increases by earnings quintile. A little more than $82 \%$ of those in the lowest earnings quintile in 2019 were employed in February 2020 compared to about $95 \%$ of those in the highest earnings quintile. As is discussed more below, these February rates are in line with historical rates of those remaining employed by quintile.

However, starting in March 2020, the proportion of workers who remained employed declined for all of the earnings quintiles, with the lowest earnings quintile suffering the largest decline in employment. The proportion of workers in the lowest earnings quintile who remained employed dropped 3.9 percentage points between February and March and fell another 23.6 percentage points between March and April 2020. In comparison, the proportion of those in the second earnings quintile who remained employed fell 1.2 percentage points between February and March and an additional 14.6 percentage points between March and April 2020. The decline for the upper quintile was much less severe; the proportion of those who remained employed falling 0.2 percentage points between February and March and an additional 5.2 percentage points between March and April 2020. Following April, employment partially recovered for all five quintiles, but as of November, employment loss was still greatest for the lowest two quintiles. By November only $75.3 \%$ of those in the lowest earnings quintile were working and $85.3 \%$ of those in the second lowest quintile. In comparison $93.4 \%$ of those in the highest earnings quintile and $92.6 \%$ of those in the fourth earnings quintile were working in November. Consistent with research based on less representative private data, the estimates from the CPS thus indicate quite clearly that the employment declines during the pandemic have fallen disproportionately on workers in the lowest earnings quintiles. The CPS estimates also are in accord with the CES estimates presented above that indicate that it was the establishments with the lowest average wages that experienced the largest decline in employment. ${ }^{7}$

To provide a frame of reference for the employment pattern in 2020, Fig. 5 shows analogous results for 2015 to 2019 averaged. The main takeaway from Fig. 5 is that even during normal economic times the percentage of individuals who are still employed from one year to the next is not the same across earnings quintiles. Individuals in the lowest quintile are less likely than individuals in the other four quintiles to be employed the following year. From February to November, the 5-year-average percent still employed in the lowest quintile varies between $79.8 \%$ and $81.4 \%$ across months, while the percent still employed for the other four quintiles varies between $89.4 \%$ and $95.4 \%$. Figure 4 thus overstates the effect of the pandemic on employment and this overstatement is largest for low-earning workers. Figure 6 displays the

\footnotetext{
${ }^{7}$ Even if employment declines were not concentrated among low-wage establishments, we would still see greater declines in the employment of low-wage workers if low-wage workers were more likely to be laid off than their higher-wage co-workers.
} 


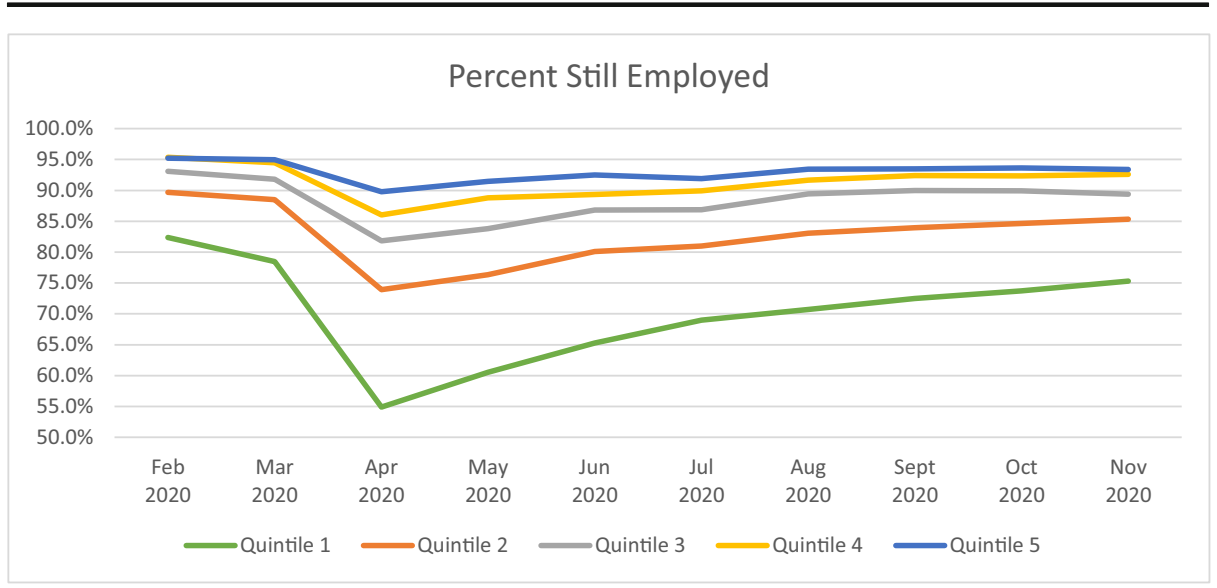

Fig. 4 Percent of those Employed in 2019 who are Employed in 2020, CPS Data

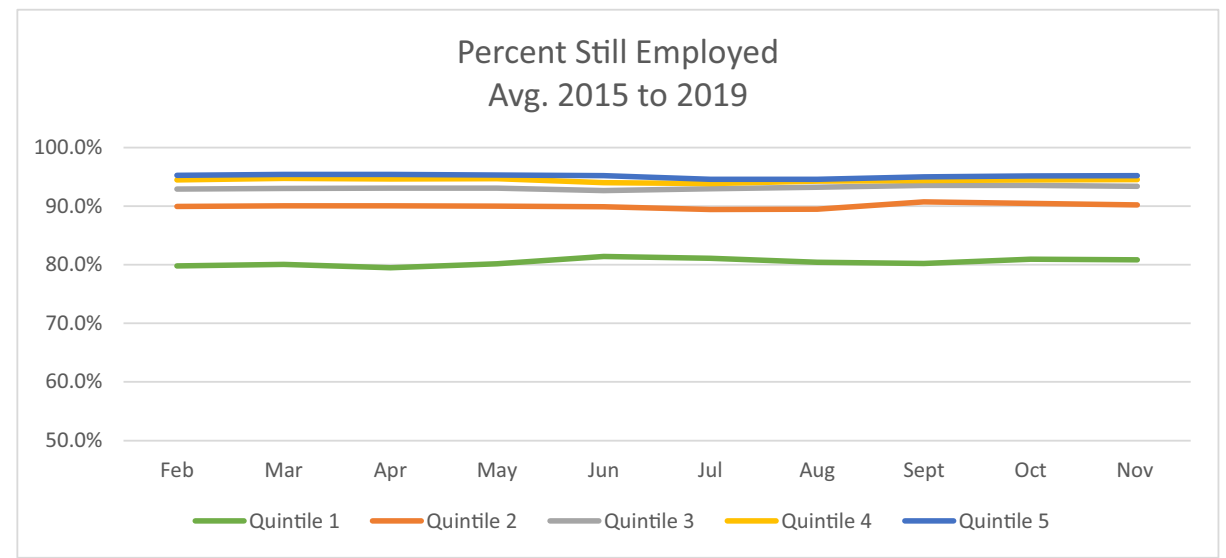

Fig. 5 Average from 2015 to 2019 of the Percent of those Employed in the Previous Year who are Employed in the Current Year, CPS Data

proportion of workers who remained employed by earnings quintile normalizing the estimates by subtracting off the 5-year-average percentage remaining employed within a quintile. This normalization does not affect the overall pattern across the earnings quintiles. Workers in the lowest earnings quintile suffered the largest losses early in the recession and although somewhat muted by the normalization, the decline in the proportion of workers who remained employed in the lowest earnings quintile still was three times larger than the decline for the highest earnings quintile in November. Given the persistent differences in the percentage of workers remaining employed by earnings quintile, the remaining analysis for 2020 is normalized by subtracting off the appropriate 2015-to-2019 average percentage of those remaining employed.

Figure 7 shows the employment rate by the major industry group that the respondent worked in during 2019, using the same earnings cutoffs across industries. ${ }^{8}$ Similar to the patterns

\footnotetext{
${ }^{8}$ In the CES, detailed industries are divided into NAICS sectors, while CPS uses major industry groups. These classifications are not exactly 1-to-1.
} 


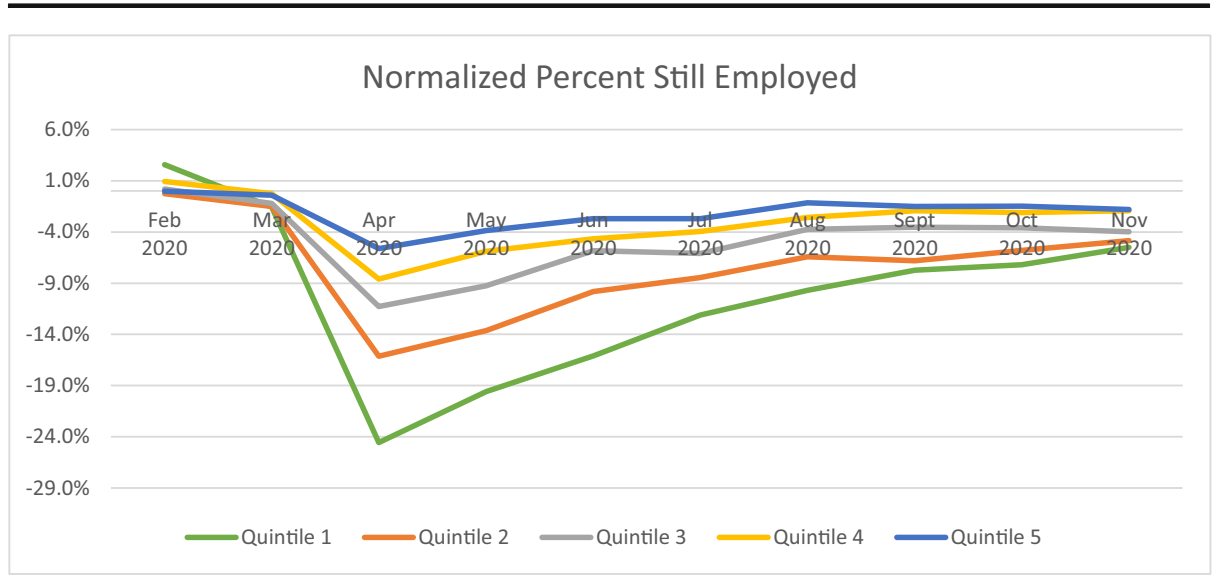

Fig. 6 Percent of those Employed in 2019 who are Employed in 2020, Normalized using Data from 2015 to 2019, CPS Data

observed in Fig. 3 using the establishment data from the CES, and similar to the overall results observed in Fig. 6 using the CPS, the key result holds: even within industry, the lowest quintile earners had the biggest initial drop in its employment rate, as well as the most employment to recover as of November in order to return to the baseline February 2020 employment rate. As of November, the lowest earnings quintile's biggest employment gaps relative to February are in Other Services, Leisure and Hospitality, Education and Health Services, and Information-a pattern similar to that in CES data. Several of these sectors are low earnings sectors. Nevertheless, the finding that low earnings workers were disproportionately harmed in every sector provides further corroborating evidence that the worse employment outcomes for low earnings individuals are not just due to them being heavily concentrated in hard-hit low wage industries. Low wage workers suffered larger employment losses within industries, too.

\section{Decomposition of Employment Change in the CPS}

Similar to our CES analysis, we decompose the change in CPS employment into across-industry and within-industry components. Note, however as discussed above, even in normal times, labor turnover means that not all workers employed in a given year will also be employed in the subsequent one and the percentage of workers remaining employed varies by earning quintile. To isolate the effect of the pandemic, we normalize by differencing across years. That is, we obtain a better estimate for the effect of the pandemic simply by subtracting the 5-year-average percentage of workers employed a year earlier who are still employed in the current year from the percentage of workers employed in 2019 who are still employed in 2020. We modify our decomposition accordingly. Specifically, we perform a decomposition for both the year 2020 and the decomposition for each year from 2015 to 2019 (prior to the pandemic) and subtract the average of the 2015 to 2019 components of employment change from the same components in 2020.

Slightly modifying the notation used for the CES decomposition, the shares for the CPS decomposition now have a year component such that the change in industry $k$ 's share of still 


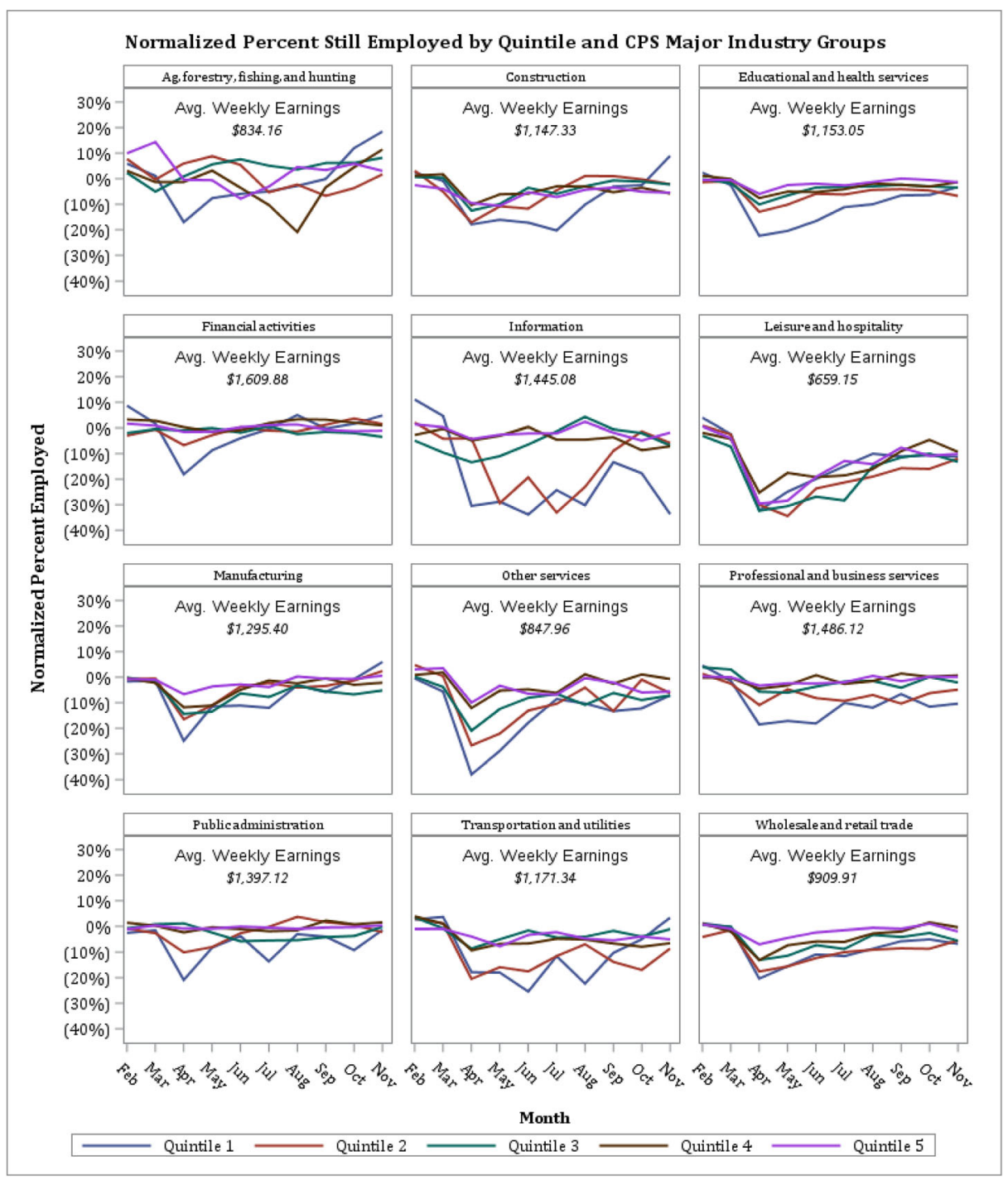

Fig. 7 Industry Percent Employed, Normalized using Data from 2015 to 2019, CPS Data. Note: The mining major industry group is excluded from Fig. 7 due to an insufficient amount of sample

employed in year $y$ vs. total employed in year $y$ - 1 for wage quintile $j$ in month $t$ is given by

$$
s_{k j t y}-s_{k j t y-1}=\frac{E_{k j t y}}{N_{k t y}}-\frac{E_{k j t y-1}}{N_{k t y}-1}
$$

Similarly, the change in still employed in year $y$ vs. total employed in year $y-1$ in major industry group $k$ in month $t$ is given by

$$
N_{k t y}-N_{k t y-1}
$$


Equation (8) can then be written as

$$
\% \Delta W_{j t y}=\frac{\sum_{k}\left[\left(s_{k j t y}-s_{k j t y-1}\right) N_{k t y}+s_{k j t y-1}\left(N_{k t y}-N_{k t y-1}\right)\right]}{W_{j y-1}}
$$

where the denominator, $W_{j y-1}$, is the annual CPS employment level for individuals in earnings quintile $j$, in the previous year $y-1$.

Using the same form as Eq. (11), the decomposition of the average percentage of workers who were employed a year earlier who are still employed can be written as

$$
\% \Delta \bar{W}_{j t y-1}=\frac{\sum_{k}\left[\left(\bar{s}_{k j t y-1}-\bar{s}_{k j t y-2}\right) \bar{N}_{k t y-1}+\bar{s}_{k j t y-2}\left(\bar{N}_{k t y-1}-\bar{N}_{k t y-2}\right)\right]}{\bar{W}_{j y-2}}
$$

where the bar over a variable denotes a 5-year average. For example, $\bar{s}_{k j t y-1}$ is the average share of industry $k$ 's workers still employed in wage quintile $j$, in month $t$ for reference year $y-1$. Specifically for our analysis $y-1$ equals the average over 2015-2019 and $\bar{s}_{k j t y-2}$ is the average share of industry $k$ 's total employed in wage quintile $j$, in month $t$ for prior year $y-2$, where $y-2$ equals the average over 2014-2018.

The final normalized decomposition is the difference between $\% \Delta W_{j t y}$ and $\% \Delta \bar{W}_{j t y-1}$, which yields

$$
\begin{aligned}
\% \Delta W_{j t y}-\% \Delta \bar{W}_{j t y-1}= & \sum_{k}\left[\frac{\left(s_{k j t y}-s_{k j t y-1}\right) N_{k t y}}{W_{j y-1}}-\frac{\left(\bar{s}_{k j t y-1}-\bar{s}_{k j t y-2}\right) \bar{N}_{k t y-1}}{\bar{W}_{j y-2}}\right] \\
& +\sum_{k}\left[\frac{s_{k j t y-1}\left(N_{k t y}-N_{k t y-1}\right)}{W_{j y-1}}-\frac{\bar{s}_{k j t y-2}\left(\bar{N}_{k t y-1}-\bar{N}_{k t y-2}\right)}{\bar{W}_{j y-2}}\right]
\end{aligned}
$$

The first term in Eq. (13) denotes the pandemic-induced employment change in earnings quintile $j$ stemming from a shift in the share of employment in each major industry group attributed to earnings quintile $j$. The second term denotes the change in employment due to changes in employment across industry groups.

The normalized decomposition results for the CPS are presented in Table 5 for select months. (Appendix Table 3 contains the estimates for every month.) Similar to the CES results, for each earnings quintile across months, the majority of the employment loss is explained by changes in sectoral employment. For the two lowest earnings quintiles, the employment loss from shifting sectoral employment is amplified by a loss stemming from reduced employment within major industry groups. For April, 32\% of the decline in employment for workers in the lowest earnings quintile was due to these workers' employment shares declining within industries. This is comparable to the $24 \%$ that we see in the CES during that same time period. The within-industry employment share continued to account for a substantial portion of the lowest wage quintile's employment loss through October, where the 
Table 5 Normalized CPS Decomposition by Major Industry Group

\begin{tabular}{|c|c|c|c|}
\hline Wage quintile & Employment change (\%) & Due to between-group reallocation (\%) & $\begin{array}{l}\text { Due to within-group } \\
\text { reallocation }(\%)\end{array}$ \\
\hline \multicolumn{4}{|l|}{ A. April 2020} \\
\hline$<\$ 444$ & -24.6 & -16.7 & -7.8 \\
\hline$\$ 444-\$ 680$ & -16.1 & -13.8 & -2.4 \\
\hline$\$ 680-\$ 978$ & -11.3 & -12.7 & 1.5 \\
\hline$\$ 978-\$ 1518$ & -8.6 & -12.0 & 3.5 \\
\hline$>\$ 1518$ & -5.6 & -10.9 & 5.3 \\
\hline \multicolumn{4}{|l|}{ B. July 2020} \\
\hline$<\$ 444$ & -12.1 & -9.4 & -2.7 \\
\hline$\$ 444-\$ 680$ & -8.4 & -7.0 & -1.4 \\
\hline$\$ 680-\$ 978$ & -6.1 & -6.0 & -0.1 \\
\hline$\$ 978-\$ 1518$ & -4.0 & -5.8 & 1.8 \\
\hline$>\$ 1518$ & -2.7 & -5.1 & 2.4 \\
\hline \multicolumn{4}{|l|}{ C. October 2020} \\
\hline$<\$ 444$ & -7.2 & -5.4 & -1.8 \\
\hline$\$ 444-\$ 680$ & -5.8 & -4.0 & -1.8 \\
\hline$\$ 680-\$ 978$ & -3.6 & -3.7 & 0.1 \\
\hline$\$ 978-\$ 1518$ & -2.1 & -3.7 & 1.6 \\
\hline$>\$ 1518$ & -1.5 & -3.5 & 2.0 \\
\hline
\end{tabular}

percentage was $25 \% .^{9}$ The second lowest wage quintile had a steady rise in this percentage, going from $15 \%$ of the employment loss explained by a reduction in the share of employment within industry in April, to $17 \%$ in July, to $31 \%$ in October.

The reduction in the employment share of low wage workers within industries in large part likely reflects employment losses in low paying occupations. ${ }^{10}$ The CPS has information on a worker's occupation as well as industry. As is the case with industries, some occupations have been hit much harder than others during the pandemic recession. Table 6 shows the results of a decomposition analysis when sectors are defined by both major industry group and major occupations. ${ }^{11}$ Relative to the decomposition that includes only industry, including occupation does reduce the lowest earnings quintile's employment loss attributed to a decline in its withinsector employment share, but not by as much as one might have expected if occupation was the predominant influence. In April, for example, 23\% of the decline in employment for workers in the lowest earnings quintile shows up as declines within industry-occupation sectors shares, compared to $32 \%$ in the industry-only decomposition.

A question that naturally arises is whether the reallocation of employment across industries is primarily due to industry effects or the fact that different industries have different occupational structures. To explore this we estimate linear regressions for each wage quintile with separate industry and occupation controls. Even controlling for occupation, many of the

\footnotetext{
$\overline{9}$ November saw a sharp reduction in this component of employment loss. Specifically, $5 \%$ of the lowest earnings quintile's employment loss in November is explained by a reduction in its share of employment within major industry groups, compared to the $31 \%$ that we see in the CES as of November. Further analysis of the data reveals that a major cause of the CPS change was the lowest wage quintile's increased share of employment in the education and health industry group. The results for November should be viewed with some caution since the sample size in November is about half the sample size in most other months. The results in November are unbiased but are subject to larger sample variance.

${ }^{10}$ It might also reflect employment reallocation among industries defined by a more detailed industry classification within the major industry groups.

${ }^{11}$ Crossing the 12 industry groups with the 10 major occupations yields 120 sectors.
} 
Table 6 Normalized CPS Decomposition by Major Industry and Major Occupation Group

\begin{tabular}{llll}
\hline Wage quintile & Employment change $(\%)$ & $\begin{array}{l}\text { Due to between-group } \\
\text { reallocation }(\%)\end{array}$ & $\begin{array}{l}\text { Due to within-group } \\
\text { reallocation }(\%)\end{array}$ \\
\hline A. April 2020 & & & -5.7 \\
$<\$ 444$ & -24.6 & -18.8 & -0.7 \\
$\$ 444-\$ 680$ & -16.1 & -15.5 & 1.4 \\
$\$ 680-\$ 978$ & -11.3 & -12.7 & 2.2 \\
$\$ 978-\$ 1518$ & -8.6 & -10.8 & 2.8 \\
$>\$ 1518$ & -5.6 & -8.4 & \\
B. July 2020 & & & -1.6 \\
$<\$ 444$ & -12.1 & -10.5 & -0.6 \\
$\$ 444-\$ 680$ & -8.4 & -7.9 & -0.3 \\
$\$ 680-\$ 978$ & -6.1 & -5.8 & 1.1 \\
$\$ 978-\$ 1518$ & -4.0 & -5.1 & 1.3 \\
$>\$ 1518$ & -2.7 & -4.0 & -0.9 \\
C. October 2020 & & & -1.2 \\
$<\$ 444$ & -7.2 & -6.3 & 0.0 \\
$\$ 444-\$ 680$ & -5.8 & -4.6 & 0.9 \\
$\$ 680-\$ 978$ & -3.6 & -3.6 & 1.2 \\
$\$ 978-\$ 1518$ & -2.1 & -3.0 & \\
$>\$ 1518$ & -1.5 & -2.7 & \\
\hline
\end{tabular}

Table 7 F-statistics for Industry Coefficients

\begin{tabular}{|c|c|c|c|c|c|c|c|c|c|c|}
\hline \multirow[b]{3}{*}{ Month } & \multicolumn{10}{|c|}{ Wage Quintile } \\
\hline & \multicolumn{2}{|l|}{$<\$ 444$} & \multicolumn{2}{|c|}{$\$ 444-\$ 680$} & \multicolumn{2}{|c|}{$\$ 680-\$ 978$} & \multicolumn{2}{|c|}{$\$ 978-\$ 1518$} & \multicolumn{2}{|l|}{$>\$ 1518$} \\
\hline & $\begin{array}{l}\text { F- } \\
\text { statistic }\end{array}$ & $\begin{array}{l}\mathrm{p} \\
\text { value }\end{array}$ & $\begin{array}{l}\text { F- } \\
\text { statistic }\end{array}$ & $\begin{array}{l}\mathrm{p} \\
\text { value }\end{array}$ & $\begin{array}{l}\text { F- } \\
\text { statistic }\end{array}$ & $\begin{array}{l}\mathrm{p} \\
\text { value }\end{array}$ & $\begin{array}{l}\text { F- } \\
\text { statistic }\end{array}$ & $\begin{array}{l}\mathrm{p} \\
\text { value }\end{array}$ & $\begin{array}{l}\text { F- } \\
\text { statistic }\end{array}$ & $\begin{array}{l}\mathrm{p} \\
\text { value }\end{array}$ \\
\hline \multicolumn{11}{|c|}{ A. For Regression Model that includes only Industry Variables } \\
\hline February & 1.23 & 0.252 & 1.17 & 0.299 & 1.99 & 0.022 & 2.63 & 0.002 & 1.52 & 0.110 \\
\hline March & 1.19 & 0.283 & 1.58 & 0.089 & 3.38 & $<0.001$ & 2.55 & 0.002 & 1.97 & 0.023 \\
\hline April & 7.31 & $<0.001$ & 8.34 & $<0.001$ & 16.08 & $<0.001$ & 9.93 & $<0.001$ & 10.53 & $<0.001$ \\
\hline May & 4.70 & $<0.001$ & 13.76 & $<0.001$ & 13.10 & $<0.001$ & 5.91 & $<0.001$ & 12.29 & $<0.001$ \\
\hline June & 3.58 & $<0.001$ & 9.19 & $<0.001$ & 10.58 & $<0.001$ & 6.14 & $<0.001$ & 7.79 & $<0.001$ \\
\hline July & 1.51 & 0.122 & 9.25 & $<0.001$ & 11.25 & $<0.001$ & 5.77 & $<0.001$ & 5.39 & $<0.001$ \\
\hline August & 2.60 & 0.002 & 7.33 & $<0.001$ & 4.35 & $<0.001$ & 6.98 & $<0.001$ & 6.85 & $<0.001$ \\
\hline September & 2.59 & 0.002 & 7.71 & $<0.001$ & 3.28 & $<0.001$ & 6.01 & $<0.001$ & 3.20 & $<0.001$ \\
\hline October & 3.18 & $<0.001$ & 5.09 & $<0.001$ & 2.69 & 0.001 & 3.06 & $<0.001$ & 3.70 & $<0.001$ \\
\hline November & 5.09 & $<0.001$ & 1.63 & 0.077 & 2.05 & 0.017 & 2.72 & 0.001 & 3.75 & $<0.001$ \\
\hline \multicolumn{11}{|c|}{ B. For Model that includes Industry and Occupation Variables } \\
\hline February & 1.24 & 0.248 & 1.18 & 0.293 & 1.99 & 0.021 & 2.63 & 0.002 & 1.53 & 0.106 \\
\hline March & 1.20 & 0.279 & 1.59 & 0.087 & 3.39 & $<0.001$ & 2.55 & 0.002 & 1.99 & 0.021 \\
\hline April & 7.34 & $<0.001$ & 8.43 & $<0.001$ & 16.14 & $<0.001$ & 10.07 & $<0.001$ & 10.66 & $<0.001$ \\
\hline May & 4.70 & $<0.001$ & 13.90 & $<0.001$ & 13.17 & $<0.001$ & 5.99 & $<0.001$ & 12.44 & $<0.001$ \\
\hline June & 3.59 & $<0.001$ & 9.21 & $<0.001$ & 10.60 & $<0.001$ & 6.18 & $<0.001$ & 7.83 & $<0.001$ \\
\hline July & 1.50 & 0.123 & 9.27 & $<0.001$ & 11.24 & $<0.001$ & 5.78 & $<0.001$ & 5.41 & $<0.001$ \\
\hline August & 2.60 & 0.002 & 7.37 & $<0.001$ & 4.37 & $<0.001$ & 7.04 & $<0.001$ & 6.88 & $<0.001$ \\
\hline September & 2.59 & 0.002 & 7.72 & $<0.001$ & 3.29 & $<0.001$ & 6.05 & $<0.001$ & 3.22 & $<0.001$ \\
\hline October & 3.18 & $<0.001$ & 5.13 & $<0.001$ & 2.70 & 0.001 & 3.07 & $<0.001$ & 3.71 & $<0.001$ \\
\hline November & 5.09 & $<0.001$ & 1.64 & 0.075 & 2.06 & 0.017 & 2.73 & 0.001 & 3.75 & $<0.001$ \\
\hline
\end{tabular}




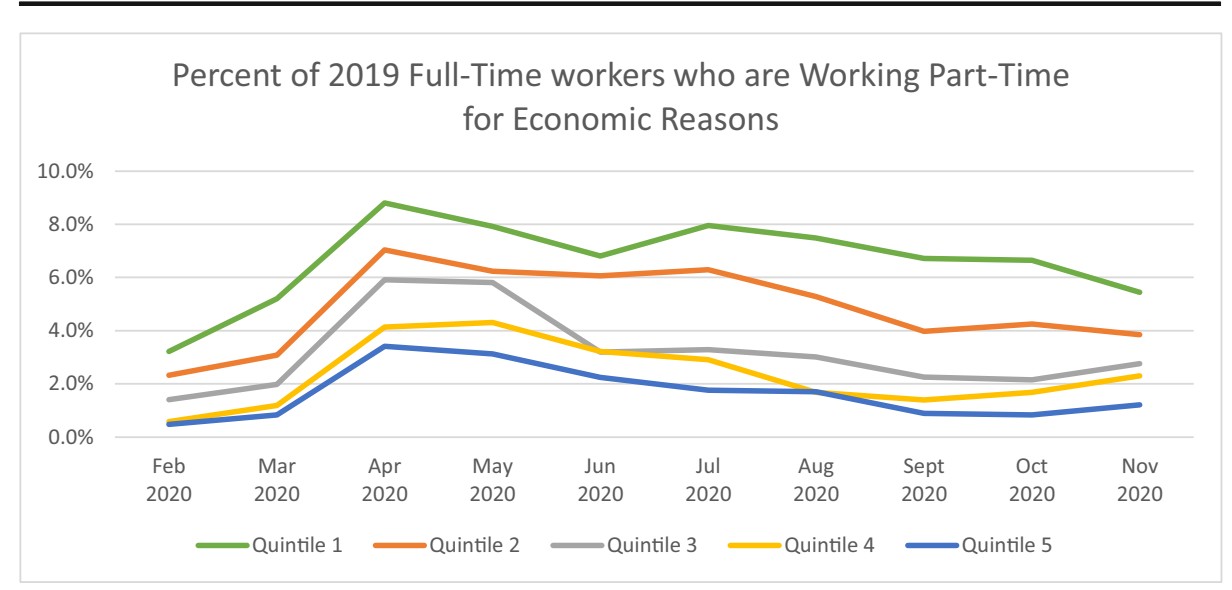

Fig. 8 Percent of 2019 Full-Time Workers Reporting Working Part-Time for Economic Reasons in 2020, CPS Data

industry variables are statistically significant. An F-test for the industry variables also indicates the industry coefficients are jointly significant even when controlling for occupations (Table 7). Furthermore, the inclusion of occupational controls does not substantially attenuate the industry effects, as the F-statistics for industry variables from a model with just industry controls and the F-statistics for the industry variables from a model with industry and occupational controls are very similar.

\section{Working Part-Time for Economic Reasons in the CPS}

Besides information on overall employment, the CPS has additional information that sheds light on workers during the pandemic who remained employed - particularly low-earning workers. For example, it is possible that even those workers who have remained employed during the pandemic are negatively affected due to their inability to work as many hours as they wished. Figure 8 presents evidence that the pandemic led to an increase in the number of individuals working parttime for economic reasons in 2020. ${ }^{12}$ Every earnings quintile experienced an increase in the percentage of those who remained employed who were working part-time for economic reasons during the pandemic. However, the upward spike in this percentage was the largest and the most sustained for workers in the lowest earnings quintile. This shows that even among those who remained employed, low wage workers were the most adversely affected by the pandemic.

\section{Additional Evidence from a Special Establishment Survey about the COVID-19 Pandemic}

A special BLS survey provides additional insights into the experience of low wage workers during the pandemic. The Business Response Survey to the Coronavirus Pandemic (BRS) is a

\footnotetext{
${ }^{12}$ Respondents are classified as working part-time for economic reasons if they report that they want full-time employment (more than $35 \mathrm{~h}$ per week), but work part-time (less than $35 \mathrm{~h}$ per week) due to a lack of opportunity for full-time work.
} 
Table 8 Percentage of Establishments Reporting Each in the Business Response Survey

\begin{tabular}{llllll}
\hline $\begin{array}{l}\text { Average } \\
\text { Wage per } \\
\text { Worker }\end{array}$ & $\begin{array}{l}\text { Told } \\
\text { Employees } \\
\text { Not to Work }\end{array}$ & $\begin{array}{l}\text { Continued Paying } \\
\text { Employees Not } \\
\text { Working }\end{array}$ & $\begin{array}{l}\text { Paid Health Insurance } \\
\text { for Employees Not } \\
\text { Working }\end{array}$ & $\begin{array}{l}\text { Increased } \\
\text { Telework for } \\
\text { Employees }\end{array}$ & $\begin{array}{l}\text { No Telework } \\
\text { Before or During } \\
\text { Pandemic }\end{array}$ \\
\hline$\$ 20 \mathrm{k}$ & 60 & 38 & 20 & 13 & 74 \\
$\$ 20 \mathrm{k}-\$ 40 \mathrm{k}$ & 56 & 50 & 39 & 23 & 63 \\
$\$ 40 \mathrm{k}-\$ 60 \mathrm{k}$ & 52 & 58 & 60 & 39 & 46 \\
$\$ 60 \mathrm{k}-\$ 80 \mathrm{k}$ & 47 & 60 & 68 & 52 & 29 \\
$\$ 80 \mathrm{k}+$ & 39 & 57 & 66 & 58 & 17 \\
\hline
\end{tabular}

Note: ' $\mathrm{k}$ ' means thousands

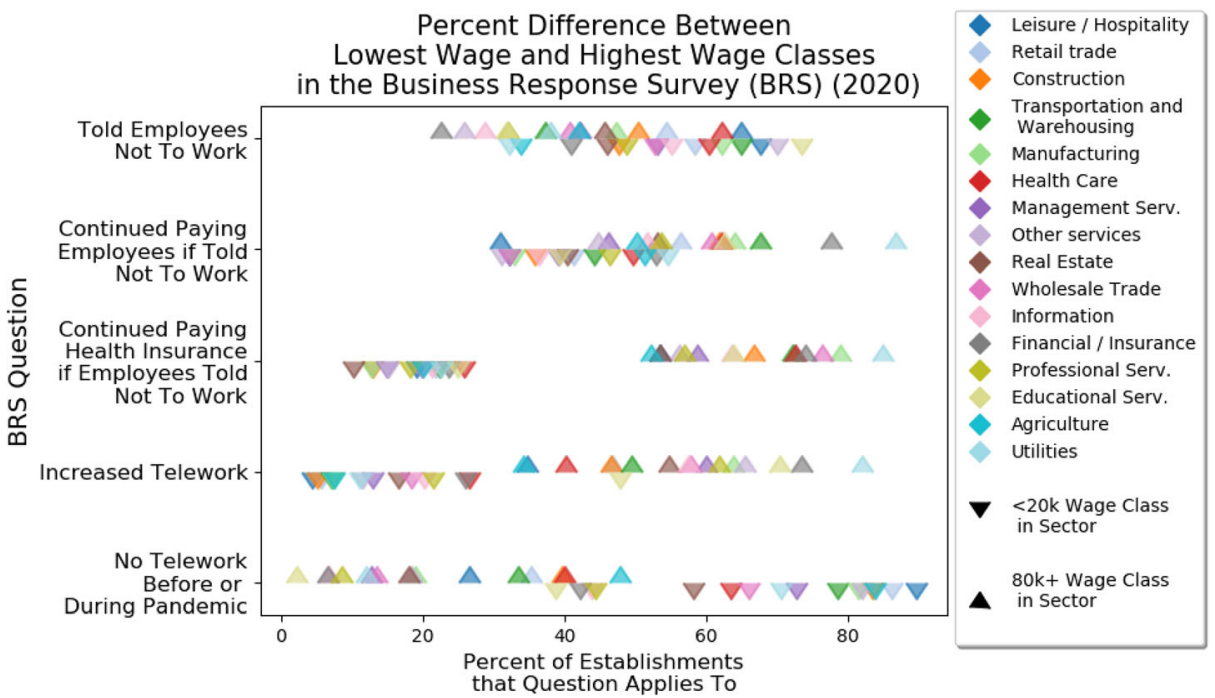

Fig. 9 Differential Responses between High- and Low-Paying Employers within Sector in the Business Response Survey

special survey of establishments conducted between July and September 2020 using an online instrument to collect responses to a series of questions related to businesses' experiences during and responses to the pandemic. ${ }^{13}$ The survey received responses from over 150,000 establishments for seven different questions. The sample was drawn from the QCEW universe of private establishments and was designed to be representative by state, sector, and size class.

We present responses to three of the seven questions collected in the survey:

- Did this business location continue to pay some or all employees who were told not to work as a result of the Coronavirus pandemic while they were not working?

- Did this business location continue to pay a portion of health insurance premiums for some or all employees who were told not to work as a result of the Coronavirus pandemic?

- Did this business location offer more opportunities for employees to telework (work remotely) as a result of the Coronavirus pandemic?

\footnotetext{
$\overline{{ }^{13} \text { More information can be found }}$ at https://www.bls.gov/brs/. Note, of course, that establishments that closed earlier during the pandemic (and remained closed) are not present in the survey.
} 
All responses are weighted using average annual employment from 2019. We classify establishments according to their industry and 2019 average wages recorded in the QCEW, as we did for the CES analysis.

Table 8 summarizes the results. The lowest-wage establishments were approximately $50 \%$ more likely than the highest-wage establishments to have told employees not to work. The highest-wage establishments were approximately 50\% more likely than the lowest-wage establishment to have continued paying at least some employees that they told not to work. Furthermore, the highest-wage establishments were more than three times as likely as the lowest-wage establishments to have paid health insurance premiums for employees told not to work. Lastly, the highest-wage establishments were more than four times as likely to report increasing telework opportunities for employees, and for the vast majority of the lowest-wage establishments (74\%), telework was not available for their employees.

The BRS results provide additional evidence that low wage workers have been hit very hard by the pandemic induced recession. Figure 9 shows that, again, these patterns are not isolated to one or two sectors - the pattern of hardship holds across most of the sectors. For each BRS response category, the figure shows a pair of up and down arrows corresponding to each sector (denoted by color). The down arrow indicates the percentage of establishments in a sector's lowest wage class fitting into the corresponding category and the up arrow is the same but for the highest wage class. There are significant differences within sectors between the lowest and highest wage classes, providing further evidence that the effects for a sector's lowest wage workers impact a broad portion of the economy; these differences are not isolated to a few sectors. Note too that the option for telework provides a partial explanation for the employment disparity across wage classes. Telework may be an important pathway for maintaining employment throughout the pandemic. Even within sectors, high wage establishments are considerably more likely than low wage establishments to offer telework and to have increased telework during the pandemic.

\section{Conclusion}

Our analysis of the CES establishment data and the CPS worker data demonstrates that the lowest average wage establishments and the lowest earning workers have borne the brunt of the recession induced by the Coronavirus pandemic. The lowest wage establishments and the lowest wage workers both saw the steepest initial declines in employment at the start of the recession and experienced the slowest subsequent recovery in employment. Further, our results indicate that these effects were not confined to a few low wage sectors, but rather that the decrease in employment for the lowest wage workers was widespread throughout the economy. Within the majority of industries, the lowest wage establishments and the lowest wage workers suffered a larger share of employment declines at the beginning of the recession and continued to experience slower growth once employment began to recover.

A decomposition of the overall employment decline of low wage establishments into the reduction stemming from declines in industries' shares of total employment and the reduction stemming from declines in the employment shares of low wage establishments within industries shows that although the majority of the overall employment decline was due to low wage industries' declining employment shares, declining employment shares of low wage establishments within industries account for a substantial portion of the overall decline. The establishment decomposition indicates that in April 2020 one-fourth (25\%) of the decline in 
employment among establishments in the lowest wage quintile was due to a decrease of these establishments' employment shares within industries. Since April 2020 this percentage ranged from $23 \%$ (in January 2021) to $46 \%$ (in May 2021).

A decomposition of the overall employment decline of low wage workers yields a similar result. The decline in employment shares within industries was particularly true for low wage workers at the start of the recession. As of April 2020, the decomposition for workers shows that $32 \%$ of the decline in employment for workers in the lowest earnings quintile was due to these workers' employment shares declining within industries; this percentage remained in the range of $22 \%$ to $33 \%$ through October 2020. The share of employment loss due to within-sector allocation was also substantial for workers in the second-lowest wage class-for example, it was $15 \%$ in April 2020 and $31 \%$ in October 2020.

The CPS data also indicate that even low wage workers who managed to hold onto their jobs have been hard hit during the pandemic induced recession. Low earning workers have been much more likely to work part time for an economic reasons than have workers in other earnings quintiles.

Examination of BRS data collected during the pandemic further illustrates the disparity between low wage and high wage workers. Among establishments that reduced their workforce, low wage establishments were much less likely to pay a portion of workers' health insurance premiums. Low wage establishments were also less likely to pay workers who were told not to work. Analysis by industry again shows that these effects are not confined to establishments in the lowest wage sectors of the economy. A comparison of the lowest and highest average wage establishments within industries shows that even in the same industry a smaller percentage of the lowest wage establishments paid either wages to workers who were told not to work or a portion of health insurance premiums for these workers.

Altogether our findings suggests that the pandemic has increased economic inequality over the months we observed. To the extent that lack of employment causes long-term earnings reductions, weakened savings, and loss of human capital, increased inequality due to the pandemic may be an issue for years to come.

Supplementary Information The online version contains supplementary material available at https://doi.org/ 10.1007/s10888-021-09506-6.

\section{References}

Bartik, A.W., Bertrand, M., Lin, F, Rothstein, J, Unrath, M.: Measuring the Labor Market at the Onset of the COVID-19 Crisis. Brookings Papers on Economic Activity, 2020 (COVID-19 and the Economy: Part One, Summer 2020), 239-268 (2020)

Cajner, T., Crane, L.D., Decker, R.A., Grigsby, J., Hamins-Puertolas, A., Hurst, E., Kurz, C., Yildirmaz, A. The US Labor Market during the Beginning of the Pandemic Recession. Brookings Papers on Economic Activity, 2020 (COVID-19 and the Economy: Part One, Summer 2020), 3-34 (2020). https://www.jstor. org/journal/broopapeeconacti

Chetty, R., Friedman, J.N., Hendren, N., Stepner, M., and the Opportunity Insights Team. The Economic Impacts of COVID-19: Evidence from a New Public Database Built Using Private Sector Data. NBER Working Paper 27431 (2020). https://doi.org/10.3386/w27431

Chetty, R., Stepner, M., Abraham, S., Lin, S., Scuderi, B., Turner, N., Bergeron, A., Cutler, D.: The association between income and life expectancy in the United States, 2001-2014. JAMA. 315(16), 1750-1766 (2016) 
Dalton, Michael, Elizabeth Weber Handwerker, and Mark A. Loewenstein. 2020. "Employment changes by employer size during the COVID-19 pandemic: a look at the Current Employment Statistics survey microdata." Monthly Labor Review, October. https://doi.org/10.21916/mlr.2020.23

Davis, S.J., Von Wachter, T.: Recessions and the costs of job loss. Brook. Pap. Econ. Act. 43(2), 1-72 (2011)

Dey, Matthew, and Mark A. Loewenstein. 2020. "How many workers are employed in sectors directly affected by Covid-19 shutdowns, where do they work, and how much do they earn?" Monthly Labor Review, April. https://doi.org/10.21916/mlr.2020.6

Dey, Matthew, Mark A. Loewenstein, David S. Piccone Jr., and Anne E. Polivka. 2020. "Demographics, Earnings, and Family Characteristics of Workers in Sectors Initially Affected by Covid-19 Shutdowns." Monthly Labor Review, June. https://doi.org/10.21916/mlr.2020.11

Heathcote, J., Perri, F., Violante, G.L.: The rise in US earnings inequality: does the cycle drive the trend? Rev. Econ. Dyn. 37, S181-S204 (2020)

Sullivan, D., Von Wachter, T.: Job displacement and mortality: an analysis using administrative data. Q. J. Econ. 124(3), 1265-1306 (2009)

Yagan, D.: Employment hysteresis from the Great Recession. J. Polit. Econ. 127(5), 2505-2558 (2019)

Publisher's Note Springer Nature remains neutral with regard to jurisdictional claims in published maps and institutional affiliations.

\title{
Affiliations
}

\section{Michael Dalton ${ }^{1} \cdot$ Jeffrey A. Groen ${ }^{1} \cdot$ Mark A. Loewenstein ${ }^{1} \cdot$ David S. Piccone Jr ${ }^{1}$ • Anne E. Polivka ${ }^{1}$}

\author{
Jeffrey A. Groen \\ Groen.Jeffrey@bls.gov \\ Mark A. Loewenstein \\ Loewenstein.Mark@bls.gov \\ David S. Piccone, Jr \\ Piccone.David@bls.gov \\ Anne E. Polivka \\ Polivka.Anne@bls.gov
}

1 U.S. Bureau of Labor Statistics, 2 Massachusetts Avenue NE, Suite 4945, Washington, DC 20212, USA 